\title{
ARTHROSCOPIC STAPLING FOR DETACHED SUPERIOR GLENOID LABRUM
}

\author{
MINORU YONEDA, ATSUSHI HIROOKA, SUSUMU SAITO, TOMIO YAMAMOTO, \\ TAKAHIRO OCHI, KONSEI SHINO
}

From the Osaka Kohseinenkin Hospital and Sumitomo Hospital, Osaka, Japan

\begin{abstract}
Superior labral tears of the shoulder involve the biceps tendon and labrum complex which may be detached, displaced inferiorly, and interposed between the glenoid and the humeral head. We have treated ten young athletes with painful shoulders due to this lesion by arthroscopic stapling.

Arthroscopy at the time of staple removal, after three to six months, showed that all the lesions had been stabilised. Clinical review at over 24 months showed an excellent or good result in $80 \%$. The two relative failures were due in one to residual subacromial bursitis, and the other to multidirectional shoulder instability.

Arthroscopic stapling can restore the shoulder anatomy, and it is recommended for active adolescent athletes with this lesion.
\end{abstract}

Injuries of the superior glenoid labrum involving the insertion of the biceps tendon are seen in athletes performing sports which require repetitive overhead use of the arm, such as baseball, tennis, and volleyball. They may also be caused by sudden forced abduction of the arm. The mechanism of the injury has been discussed by Andrews, Carson and McLeod (1985) and by Detrisac and Johnson (1986). The diagnosis can be confirmed by arthroscopy; the mode and degree of damage to the biceps tendon and labral complex (BLC) varies, and may include fraying, flap tears, a detached and 'floating' BLC, or complete disruption of that structure.

These injuries cause shoulder pain during throwing or overhead activities, especially when the entire BLC is detached and displaced inferiorly to become interposed between the glenoid fossa and the humeral head (Fig. 1,

M. Yoneda, MD, Head, Section of Shoulder Surgery

T. Yamamoto, MD, Chief

Department of Orthopaedic Surgery, Osaka Kohseinenkin Hospital, 4-2-78 Fukushima, Fukushima-ku, Osaka 553, Japan.

A. Hirooka, MD, Assistant Professor

T. Ochi, MD, Associate Professor

K. Shino, MD, Chief

Department of Orthopaedic Surgery, Osaka University Medical School, 1-1-50, Fukushima, Fukushima-ku, Osaka 553, Japan.

S. Saito, MD, Chief

Department of Orthopaedic Surgery, Sumitomo Hospital, 5-15, Nakanoshima, Kita-ku, Osaka 530, Japan.

Correspondence should be sent to Dr M. Yoneda.

(C) 1991 British Editorial Society of Bone and Joint Surgery 0301-620X/91/5187\$2.00

J Bone Joint Surg [Br] 1991 ; 73-B : 746-50.

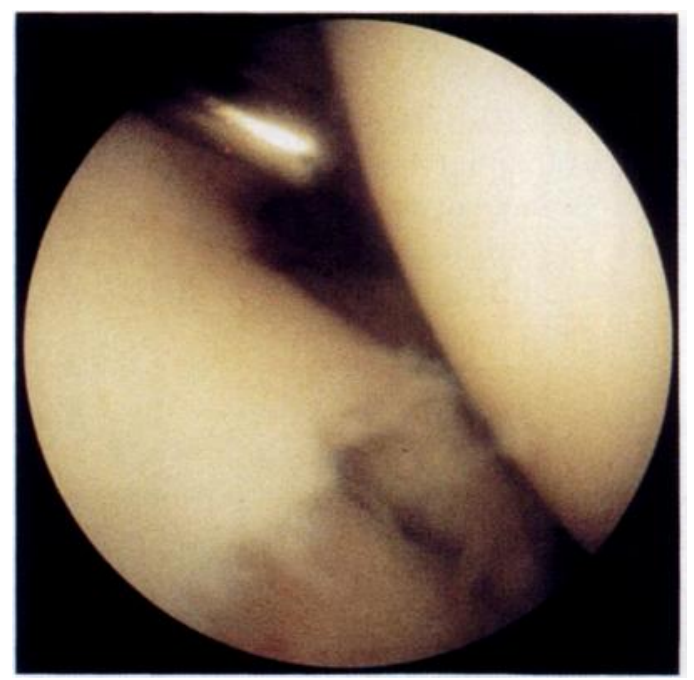

Fig. 1

Arthroscopic view of a detached and floating biceps tendon and labral complex (BLC) of the right shoulder seen through a posterior portal. The entire BLC is detached, displaced inferiorly, and interposed between the glenoid and the humeral head.

Yoneda et al 1988). This condition, 'detached and floating BLC', requires definitive treatment, usually by arthroscopic debridement or resection of the damaged labrum. However, in young 'throwing' athletes, we perform reattachment by arthroscopic stapling, to provide an anatomical reconstruction and optimal performance of the shoulder (Hirooka et al 1988).

We have reviewed our experience of arthroscopic 
stapling repair in ten young athletes by second-look arthroscopy and by clinical assessment at a minimum of two years follow-up.

\section{PATIENTS AND METHODS}

From 1986 to 1988 , ten young athletes had arthroscopic stapling for a detached BLC at Osaka Koseinenkin Hospital and Sumitomo Hospital (Table I). There were seven males and three females, and their age at operation ranged from 14 to 23 years (mean 17.8). The dominant side was affected in all cases; eight lesions were on the right and two on the left, and the injuries were sustained at baseball in seven cases, volleyball in two, and badminton in one, after sporting activity ranging from four to 13 years (mean 6.7). Four patients reported a definite previous injury.

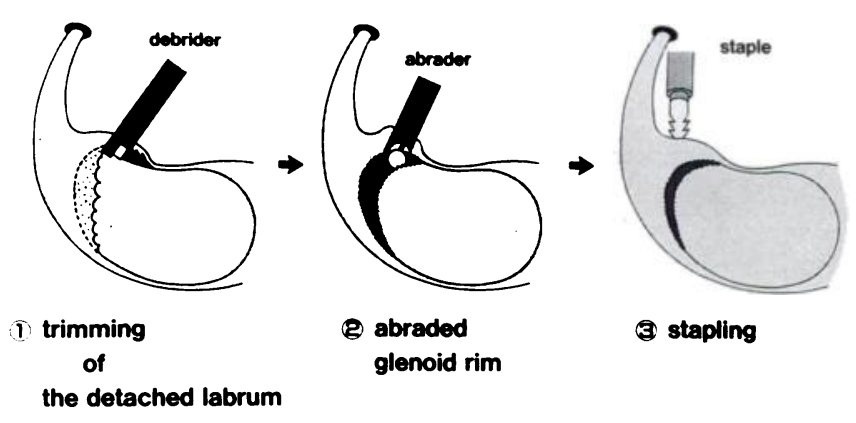

Fig. 2

Diagram of the technique of debridement, abrasion and stapling for repair of a detached BLC (see text).

All ten patients had failed to improve with conservative treatment by rest, physical therapy, muscle strengthening and stretching exercises, anti-inflammatory agents, and local steroid injections. The mean interval between the onset of symptoms and arthroscopic operation was 10.2 months (2 to 20). Second-look arthroscopy was performed at the time of staple removal, three to six months (mean 3.9) after the initial operation. The latest clinical review was at 24 to 47 months (mean 37.4) after the initial operation.

Pre-operative findings. All ten patients had shoulder pain on throwing or overhead activity; two also had pain during normal daily living, especially after participation in sports. Shoulder pain was produced by maximum forward elevation of the arm in eight patients, and by forced abduction and external rotation in nine. This pain was felt in the anterolateral aspect of the shoulder in three patients, was posterior in three, and vague in four.

Two patients had slight limitation of the range of movement. Three shoulders showed joint laxity with a positive 'sulcus sign', but no patient had a positive anterior or posterior apprehension sign. The 'clunk test' of Andrews and Gillogly (1985) was positive in two patients. One patient had no physical findings. Plain radiographs showed notching and sclerosis of the greater tuberosity of the humerus in two patients, and a Bennett lesion of the glenoid in one. Arthrography revealed an incomplete tear of the rotator cuff in one patient. CT arthrography failed to show any abnormalities of the labrum.

Operative technique. Operation is performed under general anaesthesia with endotrocheal intubation. After manual examination of both shoulders to detect instability, the patient is placed in a lateral decubitus position on a beanbag with the involved shoulder exposed. The arm is then suspended with 3 to $5 \mathrm{~kg}$ of skin traction to give approximately $70^{\circ}$ abduction and $15^{\circ}$ flexion at the shoulder.

The arthroscope is usually inserted through a

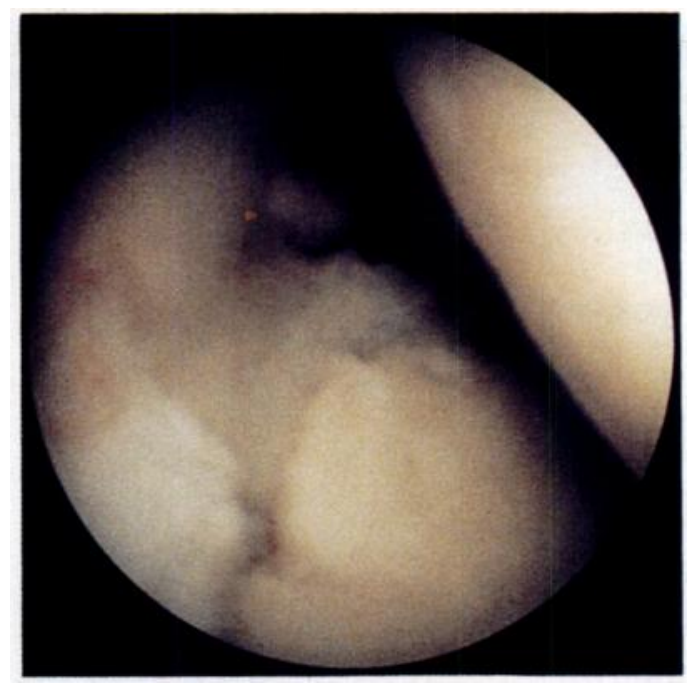

Fig. 3

Arthroscopic view after reattachment by stapling.

posterior portal and the operation performed through an anterosuperior portal. The glenohumeral joint was examined using a diagnostic probe, with specific attention to the extent of the labral detachment and to the presence of any associated pathology. We use a motorised suction debrider, and a motorised abrader to trim and prepare the lesion. Stapling is performed with the instruments of a ligamentous and capsular repair system (Instrument Makar Inc, Okemos, MI, USA), Johnson (1986). The staple head has a high profile with a diameter of $5.5 \mathrm{~mm}$. Intra-operative bleeding is controlled by adding $1 \mathrm{ml}$ of $1 \mathrm{mg} / \mathrm{ml}$ epinephrine to each litre of the normal saline used as irrigation fluid.

The torn edge of the detached and floating BLC is trimmed, the adjacent glenoid rim is abraded to bleeding bone, and the BLC is fixed with a staple driven into the 
anterosuperior scapular neck (at one o'clock in the right shoulder, Figs 2, 3 and 4). Where the detached area extends posteriorly so that fixation with one staple is inadequate, a second staple is placed posterosuperiorly (at 10 to 11 o'clock in the right shoulder).

When the presence of chronic subacromial bursitis is strongly suspected either from a positive test by injection of local anaesthetic, or an abnormal bursogram, the subacromial bursa is also arthroscoped. and stretching exercises. Graduated throwing is permitted at three to four months, with throwing at full power six months after the initial operation.

Postoperative assessment. Second-look arthroscopy was performed in all ten patients at the time of staple removal three to six months after operation (mean 3.9 months). The stability of the reattached BLC and the state of healing were carefully determined. Stability was tested by pulling on the long head of the biceps tendon and

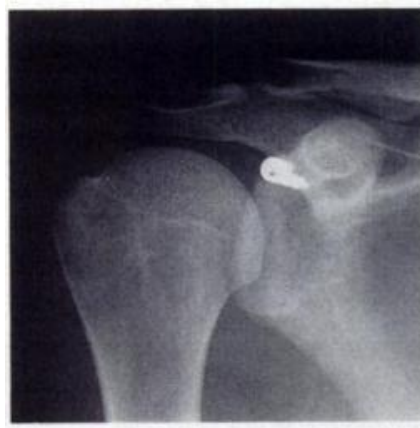

Fig. 4a

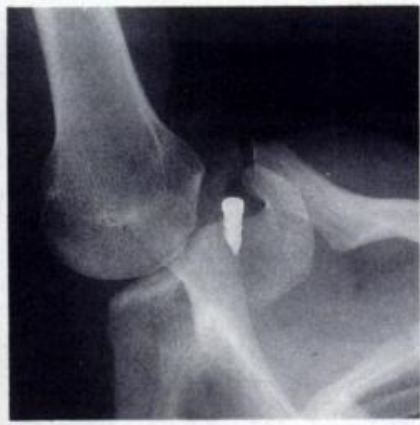

Fig. 4b

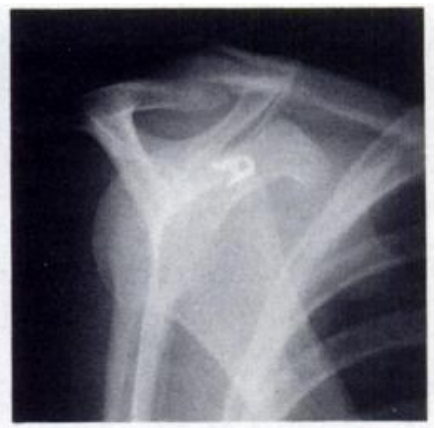

Fig. 4c

Radiographic anteroposterior (a), axial (b), and lateral scapular (c) views to show the location of the staple.

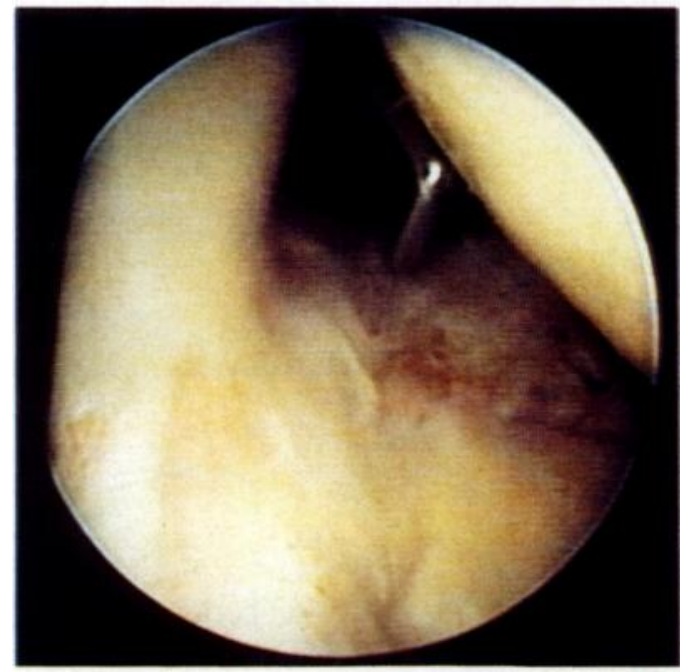

Fig. 5

Second-look arthroscopy of case 1, showing complete healing with stability of the BLC, six months after the initial operation. The head of the staple is under the fibrous tissue indicated by the tip of the probe.

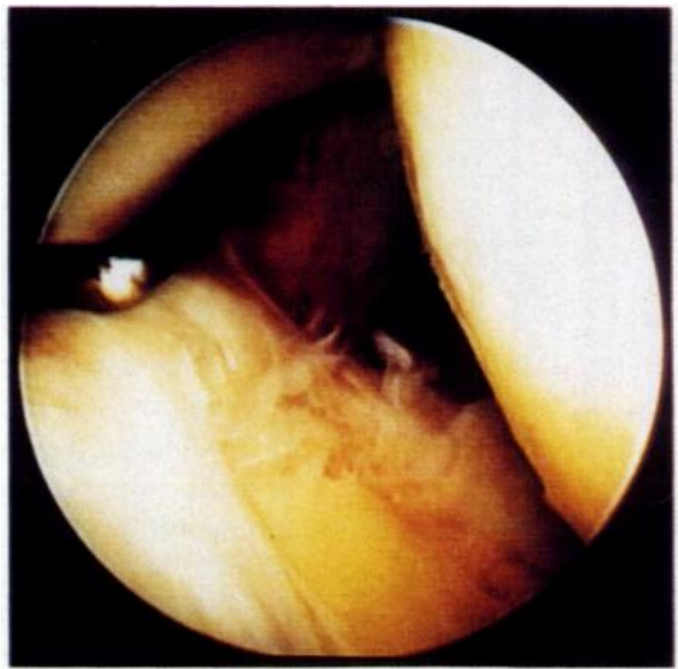

Fig. 6

Second-look arthroscopy of case 4, showing incomplete healing with stability, at four months.
Postoperative management. The shoulder is immobilised in a Velpeau-type shoulder brace for two or three weeks, but isometric exercises for the muscles of the shoulder girdle are started from the day after operation. After two to three weeks assisted forward elevation, external rotation, and Codman's pendulum exercises are started. At six weeks, the patient begins muscle strengthening mobilising the labral portion with a diagnostic probe. A fully healed wound was defined as complete continuity of the surface between the labral portion of the BLC and the abraded part of the glenoid rim.

Shoulder pain was evaluated before operation and at follow-up, by the pain rating system of Tibone et al (1985). Each patient rated pain as mild, moderate, or 
severe; its relation to function was classified as grade I for pain only during sport, grade II for pain during activities of daily living, and grade III for pain at rest.

The overall clinical results were graded as excellent, good, fair or poor, based on the degree of restoration of sporting activity. Patients with an excellent result had no pain during throwing or overhead activities and were able to return to their previous sport at the same level. Patients with a good result were able to return to previous sporting levels, but had occasional mild pain with throwing or overhead activities. Patients with a fair result had some reduction in shoulder pain, but could not return to their previous sport, while those with a poor result had no improvement.

\section{RESULTS}

Other arthroscopic findings. In three patients (cases 3, 5 and 10), in addition to the detached BLC, there was a partial thickness tear of the rotator cuff: arthroscopic cuff debridement was also performed. Two patients (cases 5 and 9) had hypertrophy and fibrosis in the subacromial bursa; one of them, case 9 , was treated by arthroscopic resection of the coracoacromial ligament and subacromial bursa at the same time as stapling of the BLC.

Second-look arthroscopy. The BLC had been stabilised in all ten patients. In four, healing was complete with continuity of the surface layer (Fig. 5). In the other six patients, superficial healing was not complete, despite good stability (Fig. 6). Only one patient had significant synovitis in the region of the BLC. In no case was there loosening of the staple or humeral head impingement.
Clinical results. Before operation, seven patients had severe shoulder pain, and three had moderate pain (Table I). At follow-up, one had severe pain, one had moderate, three mild, and five no pain. The relation of pain to function is given in Table $I$.

Eight of the ten patients had a full range of movement pre-operatively, and two patients had $10^{\circ}$ to $20^{\circ}$ loss of abduction and external rotation compared with the normal shoulder. At review nine shoulders had full movement: case 5 had a $10^{\circ}$ loss of external rotation.

The overall clinical results were excellent in five cases, good in three, fair in one, and poor in one: a successful outcome in $80 \%$. The patient with a fair result had symptoms of subacromial impingement before operation, and the poor result had a significantly positive sulcus sign of multidirectional instability pre-operatively. All ten patients have normal function for daily activities, and eight are active in athletes.

Complications. There were no cases of deep or superficial infection, no neurovascular involvement, or other significant complications.

\section{DISCUSSION}

A detached and floating BLC can be satisfactorily treated by resection alone in older inactive patients. However, where the patient is a young athlete who expects to subject his shoulder to repeated stress in the future, it is preferable to reattach the BLC to its anatomical site.

The procedure is intended to preserve the function of the tendon of the long head of biceps helping to stabilise the glenohumeral joint in concert with the rotator cuff muscles (Andrews et al 1985; Detrisac and

Table I. Details of ten patients treated for detached biceps tendon labrum complex (BLC) of the shoulder

\begin{tabular}{|c|c|c|c|c|c|c|c|c|c|c|c|c|c|c|}
\hline \multirow{3}{*}{ Case } & \multirow{3}{*}{$\begin{array}{l}\text { Age/ } \\
\text { sex }\end{array}$} & \multirow[b]{3}{*}{ Side } & \multirow{3}{*}{$\begin{array}{l}\text { Definite } \\
\text { injury }\end{array}$} & \multirow{3}{*}{$\begin{array}{l}\text { Duration of } \\
\text { symptoms (m) }\end{array}$} & \multicolumn{4}{|l|}{ Pain } & \multirow{2}{*}{\multicolumn{2}{|c|}{$\begin{array}{l}\text { Second-look } \\
\text { arthroscopy }\end{array}$}} & \multirow{3}{*}{\multicolumn{2}{|c|}{$\begin{array}{l}\text { Follow-up } \\
\left(\begin{array}{ll}\mathbf{y} \\
\mathrm{m}\end{array}\right)\end{array}$}} & \multirow{3}{*}{$\begin{array}{l}\text { Clinical } \\
\text { result }\end{array}$} & \multirow[b]{3}{*}{ Remarks } \\
\hline & & & & & \multicolumn{2}{|c|}{ Pre-operative } & \multicolumn{2}{|c|}{ Postoperative } & & & & & & \\
\hline & & & & & Severity* & Functiont & Severity & Functiont & Stable & Healing & & & & \\
\hline 1 & $19 \mathrm{~F}$ & $\mathbf{R}$ & Yes & 9 & ++ & II & + & I & Yes & Complete & 3 & 11 & Good & - \\
\hline 2 & $18 \mathrm{~F}$ & $\mathbf{R}$ & Yes & 6 & +++ & $\mathbf{I}$ & +++ & I & Yes & Complete & 3 & 8 & Poor & Sulcus sign ++ \\
\hline 3 & $23 \mathrm{M}$ & $\mathbf{L}$ & No & 13 & +++ & I & 0 & 0 & Yes & Incomplete & 3 & 7 & Excellent & RCT $\ddagger$ \\
\hline 4 & $19 M$ & $\mathbf{R}$ & No & 6 & +++ & I & + & I & Yes & Incomplete & 3 & 6 & Good & Sulcus sign + \\
\hline 5 & $16 \mathrm{M}$ & $\mathbf{R}$ & No & 11 & +++ & I & ++ & I & Yes & Incomplete & 3 & 6 & Fair & $\begin{array}{l}\text { Sulcus sign }+ \\
\text { RCT } \ddagger \text {; Bursitis }\end{array}$ \\
\hline 6 & $20 \mathrm{M}$ & $\mathbf{R}$ & No & 12 & ++ & I & 0 & 0 & Yes & Incomplete & 3 & 5 & Excellent & Bennett lesion \\
\hline 7 & $14 M$ & $\mathbf{R}$ & No & 2 & +++ & I & 0 & 0 & Yes & Complete & 3 & 2 & Excellent & - \\
\hline 8 & $17 \mathrm{M}$ & $\mathbf{L}$ & No & 20 & +++ & I & + & I & Yes & Incomplete & 2 & 4 & Good & - \\
\hline 9 & $17 \mathrm{~F}$ & $\mathbf{R}$ & Yes & 4 & ++ & II & 0 & 0 & Yes & Incomplete & 2 & 1 & Excellent & Bursitis \\
\hline 10 & $15 \mathrm{M}$ & $\mathbf{R}$ & Yes & 19 & +++ & I & 0 & 0 & Yes & Complete & 2 & 0 & Excellent & RCT \\
\hline
\end{tabular}

* pain levels: severe +++ , moderate ++ , mild + , none 0

$\dagger$ function causing pain : none 0 , sport I, normal activity II

$\ddagger$ RCT, partial rotator cuff tear 
Johnson 1986; Kumar, Satku and Balasubramaniam 1989). A longer follow-up is needed for the full assessment of the technique, but anatomical repair seems the most reasonable method of achieving optimal function, since parts of the superior and middle glenohumeral ligaments are also attached to the BLC site (Detrisac and Johnson 1986).

Snyder (1989) has recently designated superior labral tears as SLAP (superior labrum both anterior and posterior) lesions, and classified them into four types. The detached and floating BLC we have defined in the present study closely corresponds to Snyder's type II SLAP lesion, for which he has attempted stabilisation by abrasion of the glenoid rim alone. We believe that the more stable fixation achieved by stapling or suture is needed to obtain a secure repair.

We have used a metallic staple, but were concerned about possible loosening of the staple by the repetitive stresses of throwing or other overarm activities. For this reason, we removed the staple at a second arthroscopy before permitting such stress at three to six months. We found no evidence that the staples had loosened in any of the patients. In future, the use of absorbable staples (Altchek, Warren and Skyhar 1990) should eliminate the need for a second procedure. Our favourable results support the use of staples to stabilise the BLC in young athletes.

Pain in a throwing-shoulder, caused by overuse and minor trauma, tends to be produced by a combination of rotator cuff injury, subacromial bursitis, shoulder instability, and various internal derangements including labral tears (Warren 1985). This means that it can be difficult to diagnose and treat the main lesion. All our patients were young athletes, so there were probably fewer associated lesions, and the outcome was generally satisfactory. However, two cases were unsatisfactory because the pre-operative evaluation was inadequate. The one fair result was probably due to residual symptoms of impingement or chronic subacromial bursitis, both present before the operation. The poor result was due to abnormal laxity of the shoulder, and secondary impinge- ment due to instability or subluxation was the main postoperative problem in this case. In patients with a painful throwing-shoulder, even if there is an obviously detached and floating BLC, it is also necessary to evaluate instability by examination under anaesthesia and to assess the subacromial space by bursoscopy.

Conclusions. Arthroscopic stapling of a detached and floating BLC gives excellent early results, restoring the anatomy and providing good stability. It should be used for very active adolescent athletes, but it is essential to detect any associated pathology, and to treat it simultaneously.

No benefits in any form have been received or will be received from a commercial party related directly or indirectly to the subject of this article.

\section{REFERENCES}

Altchek DW, Warren RF, Skyhar MJ. Shoulder arthroscopy. In: Rockwood CA Jr, Matsen FA III, eds. The shoulder. Vol. 1. Philadelphia, etc: WB Saunders, 1990:258-77.

Andrews JR, Carson WG Jr, McLeod WD. Glenoid labrum tears related to the long head of the biceps. Am J Sports Med 1985; 13:337-41.

Andrews JR, Gillogly S. Physical examination of the shoulder in throwing athletes. In: Zarins B, ed. Injuries to the throwing arm. Philadelphia: WB Saunders, 1985:51-65.

Detrisac DA, Johnson LL. Arthroscopic shoulder anatomy. Thorofare, SLACK, 1986:21-89.

Hirooka A, Yoneda M, Wakitani S, Hayashida K. The superior glenoid labrum separation : clinical analysis and arthroscopic surgery. Cent Jpn J Orthop 1988; 32:2141-4.

Johnson LL. Shoulder arthroscopy: principles and practice. In: Arthroscopic surgery: principles and practice. Vol. 2. 3rd ed. St Louis: CV Mosby, 1986:1301-445.

Kumar VP, Satku K, Balasubramaniam P. The role of the long head of biceps brachii in the stabilization of the head of the humerus. Clin Orthop 1989; $244: 172-5$.

Snyder SJ. Superior labrum anterior and posterior lesions of the shoulder. Procs annual meeting on arthroscopic surgery of the shoulder, San Diego, 1989.

Tibone JE, Jobe FW, Kerlan RK, et al. Shoulder impingement syndrome in athletes treated by an anterior acromioplasty. Clin Orthop 1985; 198:134-40.

Warren RF. Instability of shoulder in throwing sports. Instr Course Lect $1985 ; 34: 337-48$

Yoneda M, Oda G, Miyauchi T, Fujiwara K. Clinical analyses of throwing athletes with torn superior glenoid labrums. Jap $J$ of Orthop Sports Med 1988; 7:127-30. 